\title{
Laboratory Procedures and Data Reduction Techniques to Determine Rheologic Properties of Mass Flows
}

By ROBERT R. HOLMES, JR., RICHARD J. HUIZINGA, SUSAN M. BROWN, and HARVEY E. JOBSON

U.S. GEOLOGICAL SURVEY

Water-Resources Investigations Report 93-4123 


\section{U.S. DEPARTMENT OF THE INTERIOR \\ BRUCE BABBITT, Secretary}

U.S. GEOLOGICAL SURVEY

ROBERT M. HIRSCH, Acting Director

For additional information write to:

District Chief

U.S. Geological Survey

1400 Independence Road

Mail Stop 200

Rolla, Missouri 65401
Copies of this report can be purchased from:

U.S. Geological Survey Earth Science Information Center Open-File Reports Section Box 25286, MS 517

Federal Center

Denver, Colorado 80225 


\section{CONTENTS}

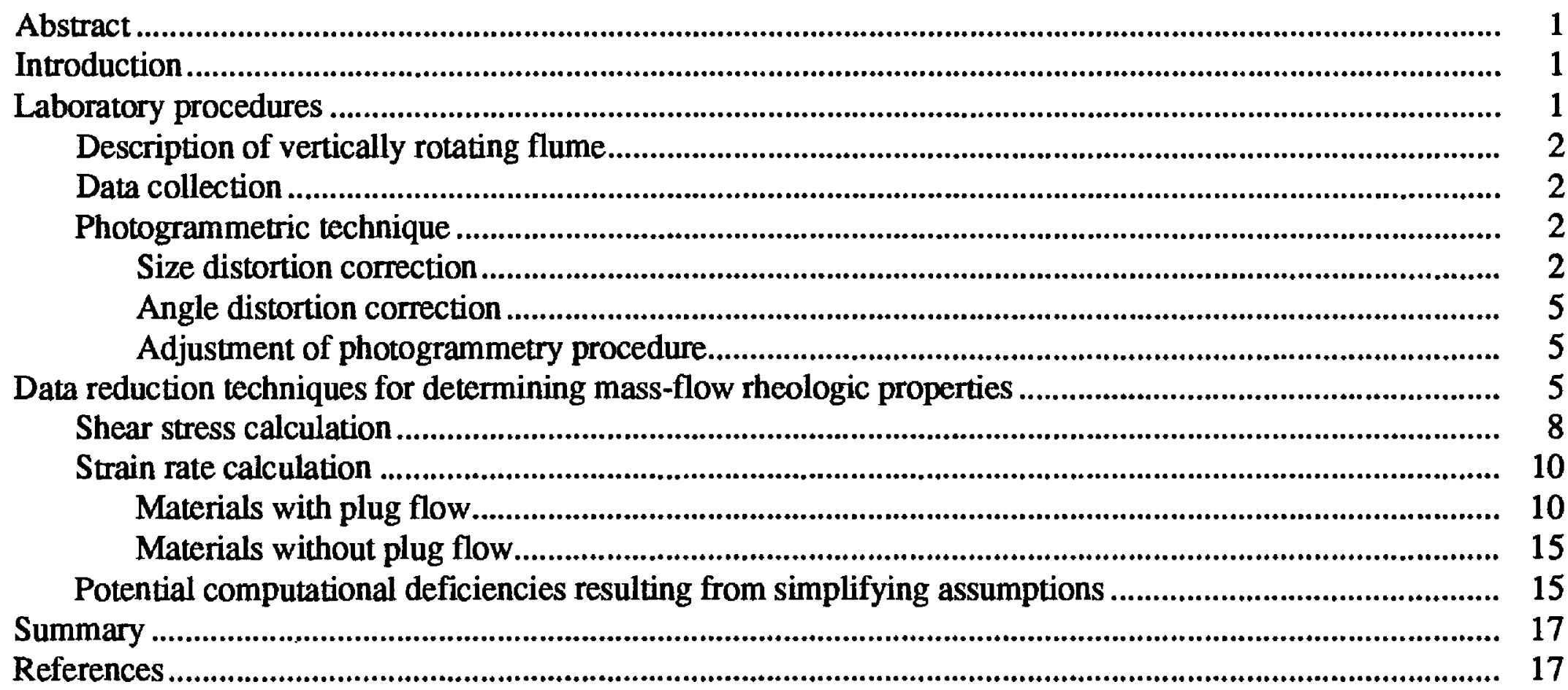

FIGURES

1. Graph showing time-independent theologic classification of fluids ................................................... 1

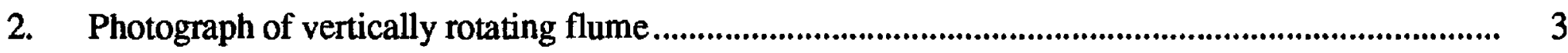

3-11. Diagrams showing:

3. Flow geometry and flow path during flume rotation

4. Position of an angularly distorted flow-profile point and the four angularly distorted grid points taken from a vertically rotating flume flow photograph

5. Actual position of flow-profile point and four grid points after corrections have been applied to the vertically rotating flume flow photograph

6. Flow material profile and example partial area

7. Free-body diagram of the forces on the flow material

8. Parabolic velocity distribution of a material with plug flow (exhibiting yield strength)

9. Parabolic velocity distribution of a material exhibiting plug flow, relative to the laboratory floor

10. Relation of velocity vectors to the vertically rotating flume bottom and the laboratory floor as a reference point

11. Parabolic velocity distribution of a material with no plug flow and the relation of the velocity vectors to the vertically rotating flume bottom and the laboratory floor 


\section{CONVERSION FACTORS}

\begin{tabular}{rll}
\hline Multiply metrlc (SI) unlt & By & Tc cbtaln Inch-pcund unit \\
\hline millimeter & 0.03937 & inch \\
square meter & 10.76 & square foot \\
meter & 3.281 & foot \\
meter per second & 3.281 & foot per second \\
dynes per square meter & $2.0892 \times 10^{-7}$ & pound per square foot \\
liter & 0.264 & gallon \\
\hline
\end{tabular}

Temperature in degrees Celsius $\left({ }^{\circ} \mathrm{C}\right)$ can be converted to degrees Fahrenheit $\left({ }^{\circ} \mathrm{F}\right)$ as follows:

$$
{ }^{\circ} \mathrm{F}=\left(1.8 \mathrm{x}^{\circ} \mathrm{C}\right)+32
$$




\section{DEFINITION OF TERMS}

Bingham plastic fluid--A fluid that exhibits a yield stress, above which the strain rate is linearly proportional to the difference between the shear stress and yield stress.

Boundary layer--Interface between flume bottom and flow material.

Debris flow--Gravity-induced mass movement intermediate between a landslide and water flood, with mechanical characteristics different from either of these processes.

Flow material--The material that constitutes the mass flow.

Liquefaction--An instability that involves the transformation of a granular material from a solid state at rest to a fluid state in movement.

Local strain rate--The strain rate at a discrete location within the mass flow. Summation of the local strain rates and division by the number of discrete measurements provides the mean strain rate for the entire mass.

Mass flow--Flow of highly concentrated suspension of sediment commonly, but not exclusively, mixed with water. Examples include mudflows, debris flows, and liquefied mine waste.

Newtonian fluid--A fluid in which the strain rate is linearly proportional to the shear stress.

Non-Newtonian fluid--A fluid in which the strain rate is not linearly proportional to the shear stress.

Plastic viscosity--The ratio of the difference between shear stress and yield stress to strain rate in a Bingham plastic fluid model.

Plug flow--A flow that contains a rigid, non-deforming zone.

Pseudoplastic fluid--A fluid in which the ratio of shear stress to strain rate decreases with increasing strain rate.

Rheology--Science of deformation and flow of matter.

Rheometer--An instrument for measuring the rheological properties of viscous fluids (shear stress and stain rate).

Sediment concentration--Ratio of the weight of solids in a mass to the total weight of solids plus water.

Shear stress--The stress, force per unit area, which is tangential to the area of interest.

Snout--The steep, bulbous front of a mass flow, usually having a greater depth than the trailing part.

Steady-state flow--A flow whose characteristics, such as velocity and depth, do not vary in time.

Strain rate--Instantaneous rate of change of velocity with distance (depth).

Tailings pile--Pile of refuse, usually consisting of clay- to sand-sized particles, left over from a mining or milling process.

Unit weight--Weight per unit volume.

Viscoplastic fluid--Fluid that possesses both viscous and plastic properties.

Viscosity--The ability of a material to resist deformation by flow defined as the ratio of shear stress to strain rate in steady-state flow.

Yield stress (strength)--The magnitude of shear stress in a material below which no permanent deformation occurs. 


\title{
Laboratory Procedures and Data Reduction Techniques to Determine Rheologic Properties of Mass Flows
}

\author{
By Robert R. Holmes, Jr., Richard J. Huizinga, Susan M. Brown, and Harvey E. Jobson
}

\section{Abstract}

Determining the rheologic properties of coarse-grained mass flows is an important step to mathematically simulate potential inundation zones. Using the vertically rotating flume designed and built by the U.S. Geological Survey, laboratory procedures and subsequent data reduction have been developed to estimate shear stresses and strain rates of various flow materials. Although direct measurement of shear stress and strain rate currently (1992) are not possible in the vertically rotating flume, methods were derived to estimate these values from measurements of flow geometry, surface velocity, and flume velocity.

\section{INTRODUCTION}

Naturally occurring mass flows, which are generally non-Newtonian, potentially could take lives and cause millions of dollars in property damage every year (Shlemon and others, 1987; Rudolfo, 1989). In the State of Missouri, there are 17 mineral tailings piles with a liquefaction potential near population centers (B.J. Swenty, Missouri Department of Natural Resources, Division of Geology and Land Survey, oral commun., 1991). Therefore, a need exists to simulate coarse-grained mass flows and delineate potential inundation hazard zones in the area of these piles. To do this, the rheologic properties of the non-Newtonian mass flows must be understood.

The purpose of this report is to document the progress in developing laboratory procedures and data reduction techniques used to determine rheologic properties of flow materials. Laboratory procedures included development of photogrammetric techniques to measure mass flow geometry in a ver- tically rotating flume (VRF). Mathematically derived data reduction techniques are based on the photogrammetry and on the geometry of the VRF. This report is part of an ongoing research effort into mass flow hazards by the U.S. Geological Survey.

\section{LABORATORY PROCEDURES}

Rheologic classification of fluids based on shear stress and strain rate ranges from Newtonian to pseudoplastic (fig. 1). Measurements of shear stress and strain rate are necessary to understand the rheology of mass flows. Although direct measurement of shear stress and strain rate currently (1992) are not possible in the VRF, methods were derived to estimate these values from measurements of flow geometry, surface velocity, and flume velocity.

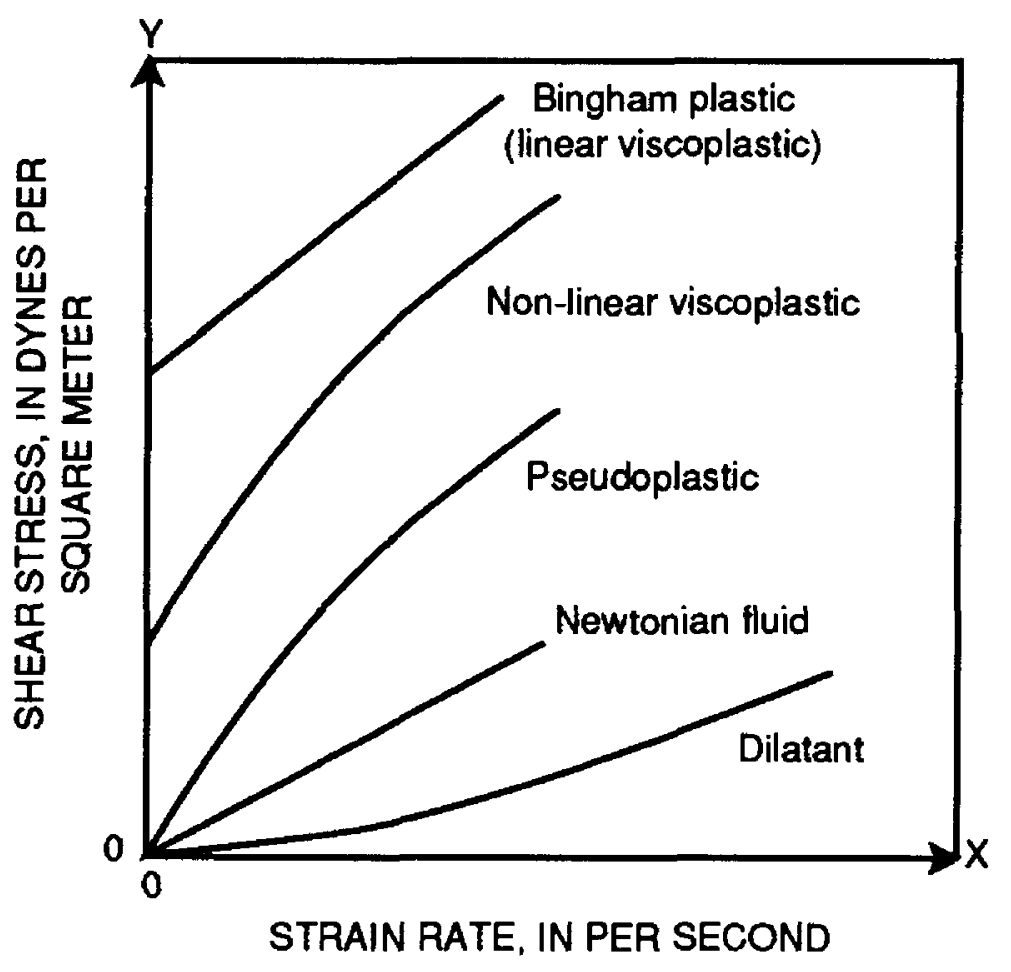

Figure 1.--Time-independent rheologic classification of fluids. 


\section{Description of Vertically Rotating Flume}

A vertically rotating flume (fig. 2 ) is used to simulate mass flows under steady-state conditions. Most actual mass flows contain coarse gravel mixed with silt, clay, and sand. The coarse material makes it difficult, if not impossible, to determine the rheologic properties of natural mass flows with a conventional theometer. However, the VRF, assuming it can accurately simulate the rheology of various materials, would be able to test the coarse-grained materials.

The VRF, a wheel-shaped flume (A in fig. 2) is $3.05 \mathrm{~m}$ (meters) in diameter, $0.61 \mathrm{~m}$ wide, and 0.43 $\mathrm{m}$ deep. A variable speed hydraulic motor (B in fig. 2 ) is used to rotate the VRF about the center hub (C in fig. 2). The resulting rotation initiates deformation of the fluid inside the VRF, inducing flow (fig. 3). By rotating the $\mathrm{VRF}$ at a constant speed, a steady-state condition is established; the material remains stationary relative to the laboratory floor, but continues to flow relative to the VRF bottom. When the steady-state condition (equilibrium) is established in the VRF, the flow can be observed for an extended time.

\section{Data Collection}

For each experiment, approximately $106 \mathrm{~L}$ (liters) of flow material and water are mixed in a tank with a pump and impeller for 24 hours. After the material is transferred to the VRF, it is mixed again by the rotation of the flume for approximately 4 minutes. Samples of approximately $1 \mathrm{~L}$ are collected before and immediately after each experiment to determine sediment concentration and unit weight. This procedure is used to check for any water loss from evaporation.

The VRF is rotated at various velocities ranging from $0.037 \mathrm{~m} / \mathrm{s}$ (meter per second) to greater than 2 $\mathrm{m} / \mathrm{s}$ for each experiment. After equilibrium is established at each velocity, data are collected for VRF velocity, surface velocity, and flow geometry at each velocity. The VRF velocity is determined by dividing the circumference of the VRF $(9.57 \mathrm{~m})$ by the time of one revolution of the VRF. An indicator is painted on the bottom of the VRF so that each rotation can be documented. Rotation time is determined by using a stopwatch.
Surface velocity is determined by measuring the time required for a float to travel a known distance. The float is placed laterally near the center of flow and in the center one-third portion of the longitudinal profile. Six or more surface velocity measurements are made for each VRF velocity to determine mean surface velocity.

Mass flow geometry is obtained from photogrammetrically determined instantaneous surface profiles of the mass flow. A 35-mm (millimeter) camera is mounted to the ceiling of the laboratory at an oblique angle to the VRF so that the intersection of the entire surface profile of the mass flow with the back wall of the VRF (D in fig. 2) is visible in the photographs.

Five photographs are taken for each velocity. The shear stress and strain rate are calculated for each photograph, and a mean shear stress and mean strain rate of all the photographs are determined that represent that particular VRF velocity.

\section{Photogrammetric Technique}

Any set of points on a plane will have unique locations on photographs taken by a camera which is fixed in space. The intersection of the flow surface with the back wall of the VRF defines a set of points on such a plane. This photogrammetric technique corrects the size and angle distortion inherent in any photograph. The scale and orientation of the coordinate system for each photograph was adjusted to match the true distances and angles between known coordinates on the VRF.

\section{Size Distortion Correction}

Targets with known locations in the plane of the back wall of the flume are located on the nonmoving part of the VRF ( $E$ in fig. 2). These targets have known coordinates and are shown on each 0.38 - by $0.61-\mathrm{m}$ photograph of the flow profile.

A correction factor for size distortion of each photograph is determined by dividing the actual distance between the top right and left targets $(0.813$ $\mathrm{m})$ by the distance measured on the photograph between the same two targets. Each measured photograph distance from the center target to various points on the photograph is multiplied by this correction factor to compensate for size distortion. 


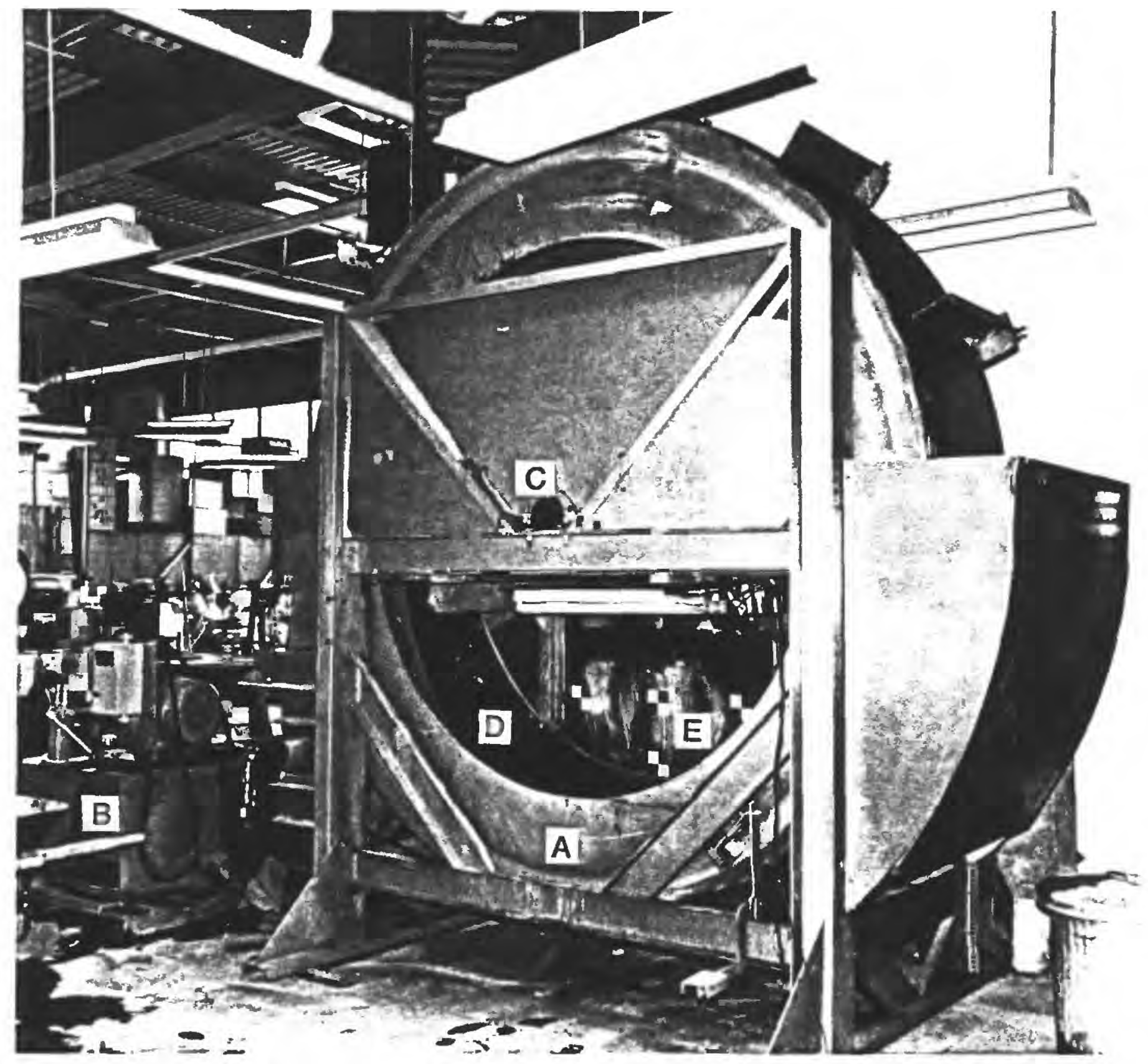

Figure 2.--Vertically rotating flume (A, flume walls; $B$, hydraulic motor; $C$, center hub; D, back wall grid system; and $E$, targets). 


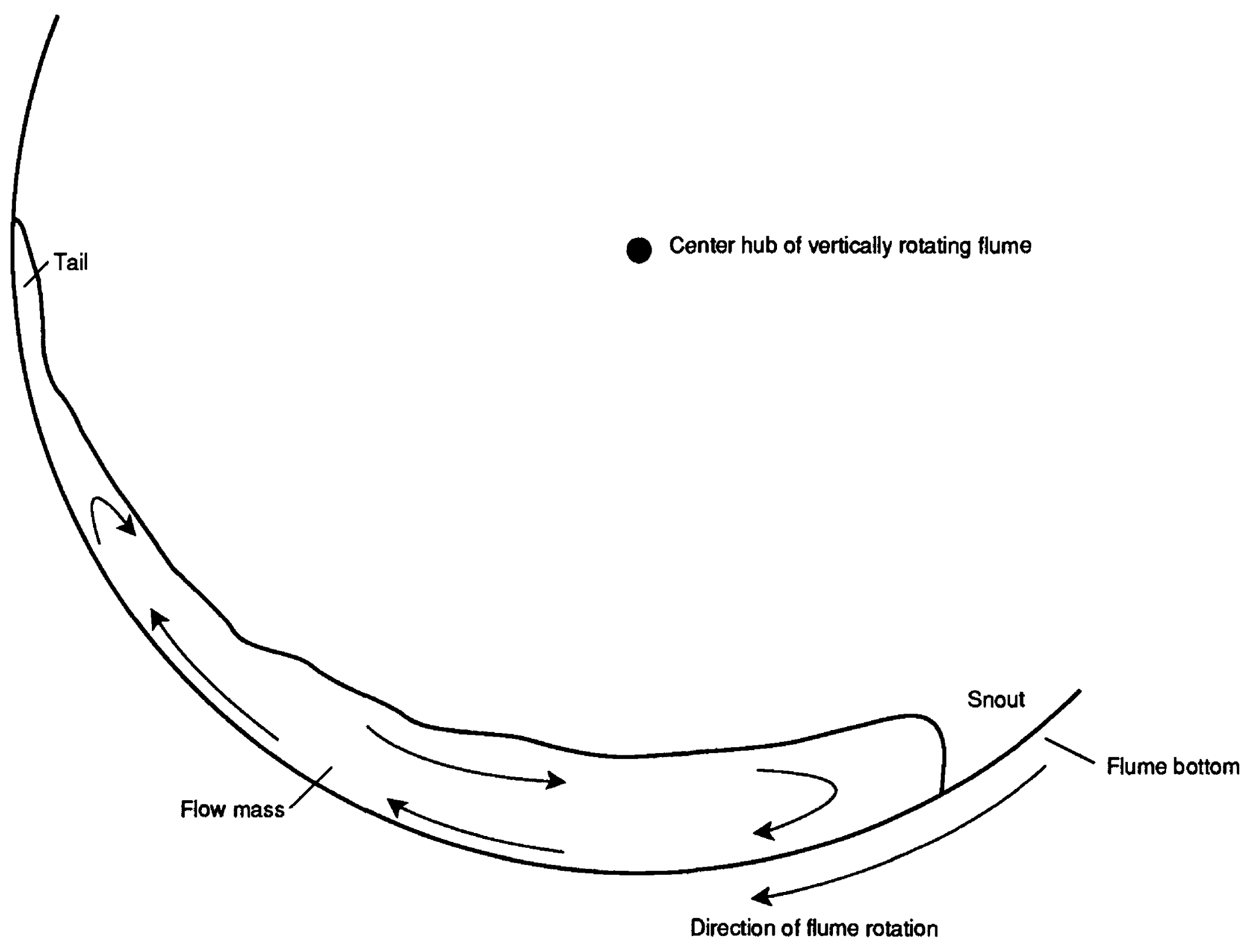

Figure 3.--Flow geometry and flow path during flume rotation. 


\section{Angle Distortion Correction}

A removable grid system on a plexiglas sheet was built to fit against the back wall inside the VRF (D in fig. 2). This 7.61-cm (centimeter) grid system provides horizontal and vertical control. The grid lines intersect at right angles, thereby giving each intersection point a known location in space and on the photograph.

The grid is installed in the VRF before each experiment, aligned so that the center vertical grid passes through the center target on the non-moving part of the VRF, and photographed. This photograph is known as the a-grid photograph. The grid is then removed from the VRF, flow material is added, and the flow simulation begins. During the experiment, several photographs are taken. These photographs are referred to as flow photographs. After the experiment, the flow material is removed, and the grid is placed along the back flume wall and photographed again. This photograph is known as the b-grid photograph and is used to be sure the camera has not moved. The grid used to correct for angle distortion is the average of the a- and b-grid photograph grid intersection locations.

The grid and flow photographs are distorted identically because of the fixed placement of the camera; therefore, the only difference between these photographs results from the enlargement process. This difference is corrected by applying the size distortion correction factor mentioned previously. To compensate for angular distortion, each flow photograph was digitally overlain with the grid photograph after each had been corrected for size distortion.

The targets and flow surface profile in the flow photograph are reproduced digitally using a digitizer table, and the coordinate systems are adjusted by use of the targets so that all data are relative to a common coordinate system. Each point on the flow photograph is surrounded by four grid intersections on the grid photograph. The actual locations of the four grid intersections are known because of the precise grid alignment before and after the experiment. The proportionate distance between the profile point and its four associated grid intersection points is determined to precisely locate the flowprofile point.

The four angularly distorted grid intersection points AP, BP, CP, and DP on the flow photograph surround the digitized flow-profile point $O P$ (fig. 4). Points $A, B, C$, and $D$ are the true locations of the four grid intersection points surrounding the actual location of the flow-profile point $O$ (fig. 5).

The horizontal proportion factor is determined by the average of distances $\overline{\mathrm{AB}}$ and $\overline{\mathrm{CD}}$ (fig. 5) divided by the average distances $\overline{\mathrm{ABP}}$ and $\overline{\mathrm{CDP}}$ (fig. 4). The vertical proportion factor is determined by the average of distances $\overline{\mathrm{CB}}$ and $\overline{\mathrm{DA}}$ (fig. 5) divided by the average of distances $\overline{\mathrm{CBP}}$ and $\overline{\mathrm{DAP}}$ (fig. 4).

Multiplying the horizontal proportion factor by $\bar{W}$ (fig. 4) gives the actual distance $\overline{\mathrm{t}}$ (fig. 5). The sum of $\bar{t}$ and $\bar{x}$ (fig. 5) is the actual horizontal distance of flow material profile point $O$ from the center target. Multiplying the vertical proportion factor by $\bar{Z}$ (fig. 4) gives the actual distance $\overline{\mathrm{r}}$ (fig. 5). The sum of $\overline{\mathrm{r}}$ and $\bar{y}$ (fig. 5) is the actual vertical distance of the flow material profile point $O$ from the center target.

\section{Adjustment of Photogrammetry Procedure}

Using the a-grid photograph, the bottom of the VRF along the back wall is digitized. The distance from the center hub to the bottom of the VRF is 1.52 $\mathrm{m}$. The location of the targets relative to the hub was adjusted such that the root mean square error of the digitized flume bottom was minimized relative to a circle with a radius of $1.52 \mathrm{~m}$. Once this adjustment is made, the photogrammetry techniques developed to remove the size and angle distortion are considered accurate.

The accuracy of the photogrammetric technique was verified at the beginning of this research by marking several points on the back wall of the VRF, and then determining their location physically and photogrammetrically. The photogrammetric technique is accurate to within $0.003 \mathrm{~m}$.

\section{DATA REDUCTION TECHNIQUES FOR DETERMINING MASS-FLOW RHEO- LOGIC PROPERTIES}

Because the direct measurement of shear stress and strain rate currently (1992) is not possible in the VRF, data reduction techniques were developed to determine rheologic properties of these flows. These techniques are based on mathematical concepts and force-balance physics. 


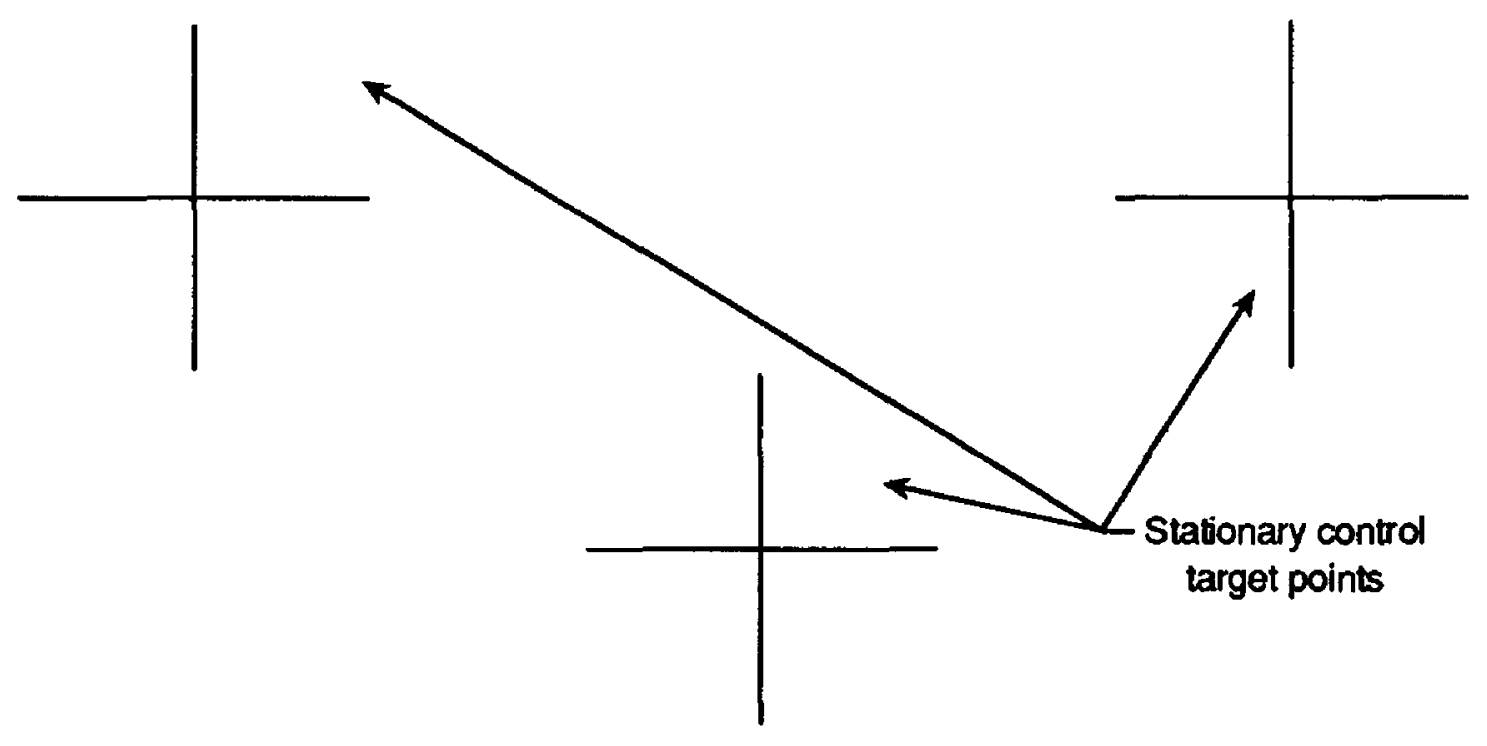

EXPLANATION
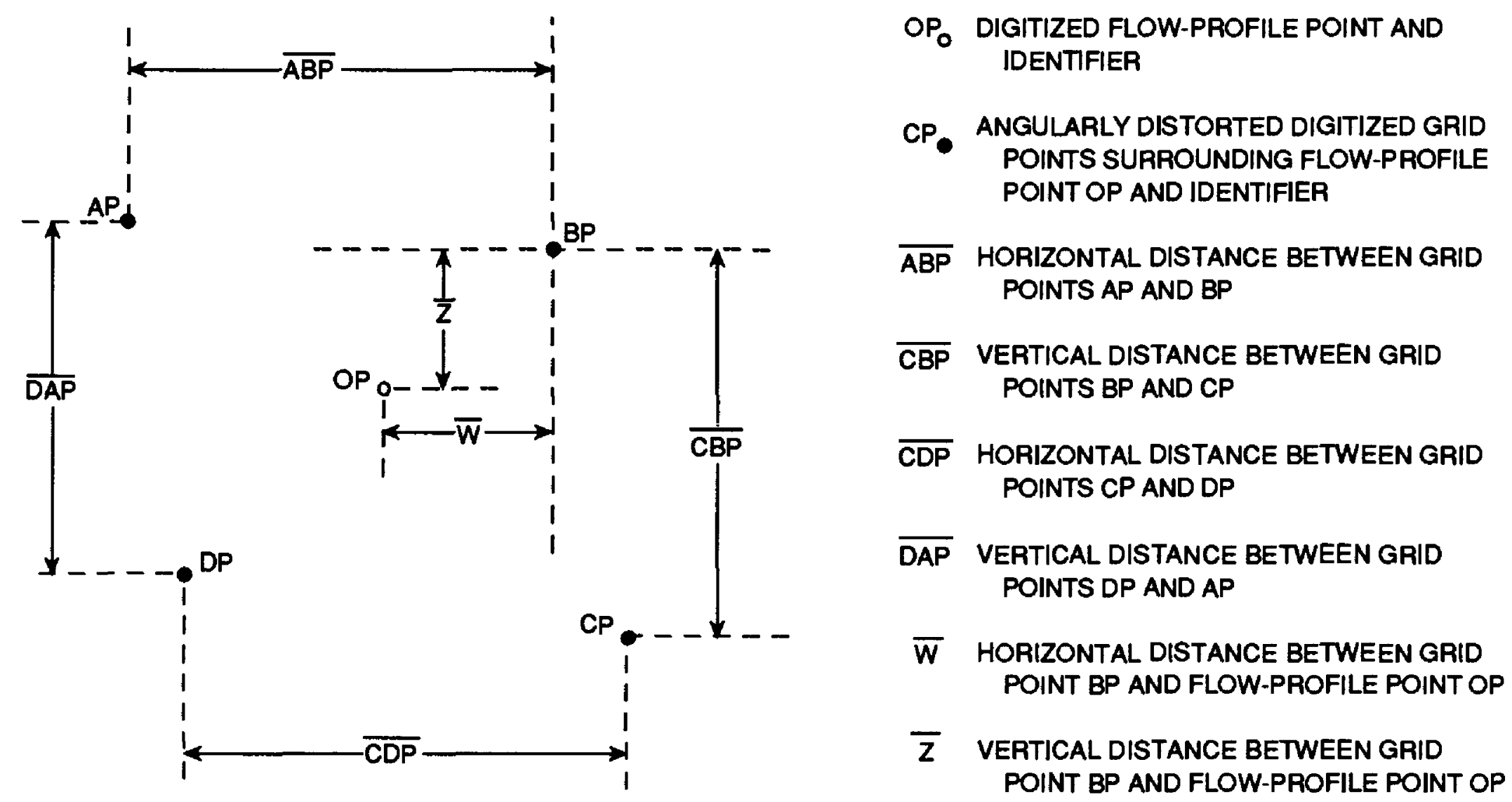

Figure 4.--Position of an angularly distorted flow-profile point and the four angularly distorted grid points taken from a vertically rotating flume flow photograph. 


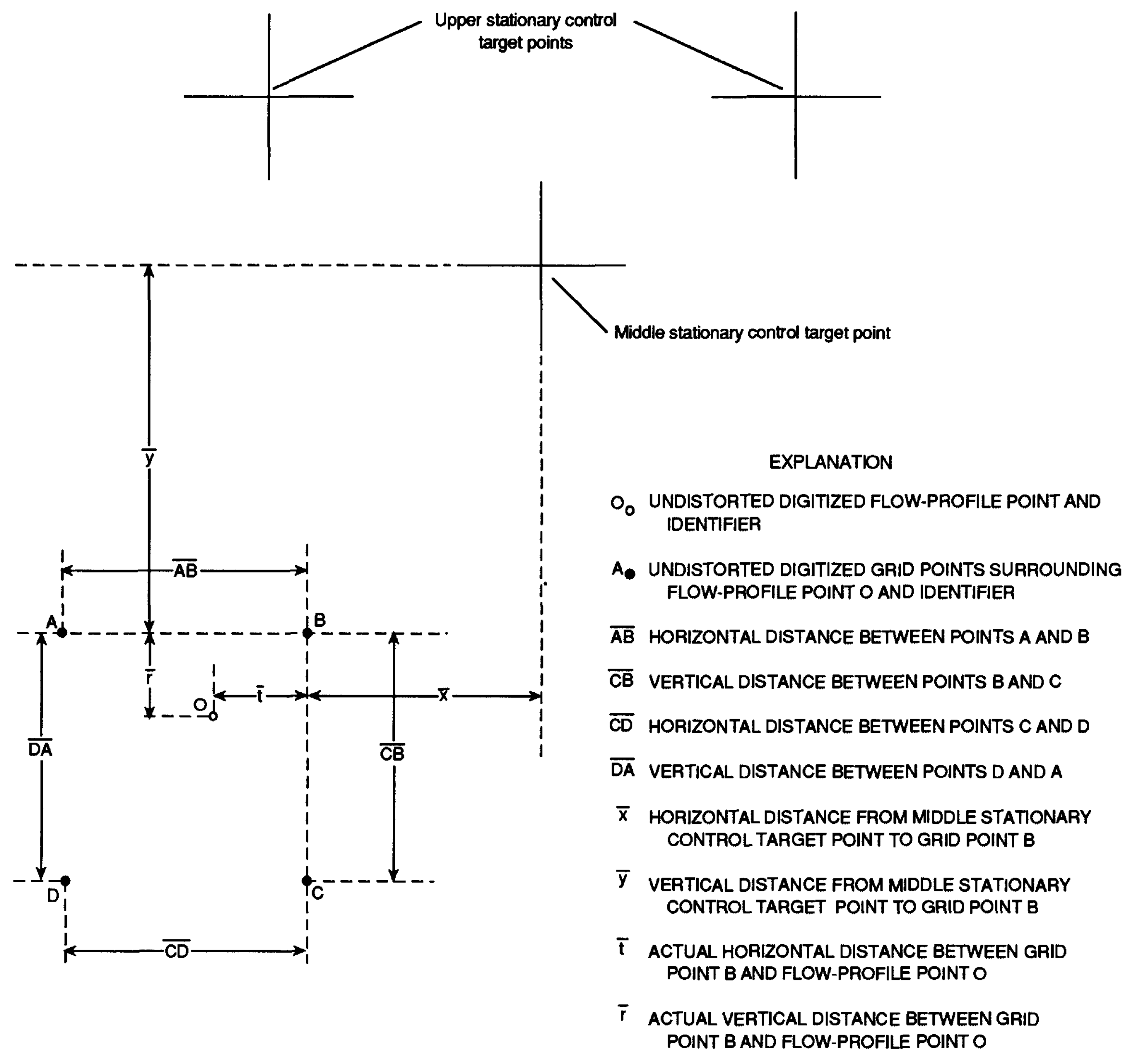

Figure 5.--Actual position of flow-profile point and four grid points after corrections have been applied to the vertically rotating flume flow photograph. 


\section{Shear Stress Calculation}

Shear stress is calculated by balancing the forces acting on the flow material during each experiment. As the VRF rotates, the center of gravity of the mass flow shifts to the left of the center of rotation (fig. 6). The unbalanced moment of the weight of the material multiplied by $\bar{X}$ (moment arm) must be balanced by the shearing forces on the bottom and sides of the material. The unbalanced moment and center of gravity of the flowing mass is computed by dividing the mass flow profile into small incremental areas ( $\Delta A$, fig. 6$)$. These incremental areas represent equal angular segments approximately $10 \mathrm{~mm}$ long. The moment of each partial area about the center hub is computed as the radius to the center of the example partial area (RCP) multiplied by the partial area $(\Delta A)$ multiplied by $\sin \theta$. Assuming a steady-state system, the sum of the moments of the partial areas about the y-axis $\left(\Sigma_{y}\right)$ multiplied by the unit weight the material represents the torque per unit width that must be balanced by the shearing forces.

A free-body diagram of the forces on the flow material is shown in figure 7 , where
$A_{s}$ is the sidewall surface area, in square meters of the mass flow profile equal to the sum of $\Delta A$;

$A_{b}$ is the bottom surface area, in square meters of the mass flow;

$\tau_{\mathrm{s}}$ is the shear stress, in dynes per square meter along the sides of the flow;

$\tau_{b}$ is the shear stress, in dynes per square meter along the bottom of the VRF;

$\phi_{s}$ is the angle to the snout, in radians;

$\phi_{t}$ is the angle to the tail, in radians;

$\theta$ is the angle to center of the mass flow from the $y$-axis, in radians;

$R_{c}$ is the radius, in meters to the center of the mass flow;

$W$ is the width, in meters of the VRF;

WT is the weight of flow, in dynes; and

$R$ is the radius, in meters to the VRF bottom.

Because the flow is assumed to be steady state, a summation of the moments leads to an equation for the average shear stress $(\tau)$ along the bottom of the VRF. It can be shown from figure 7 that

$$
A_{b}=R \times W \times\left(\phi_{s}+\phi_{t}\right) .
$$

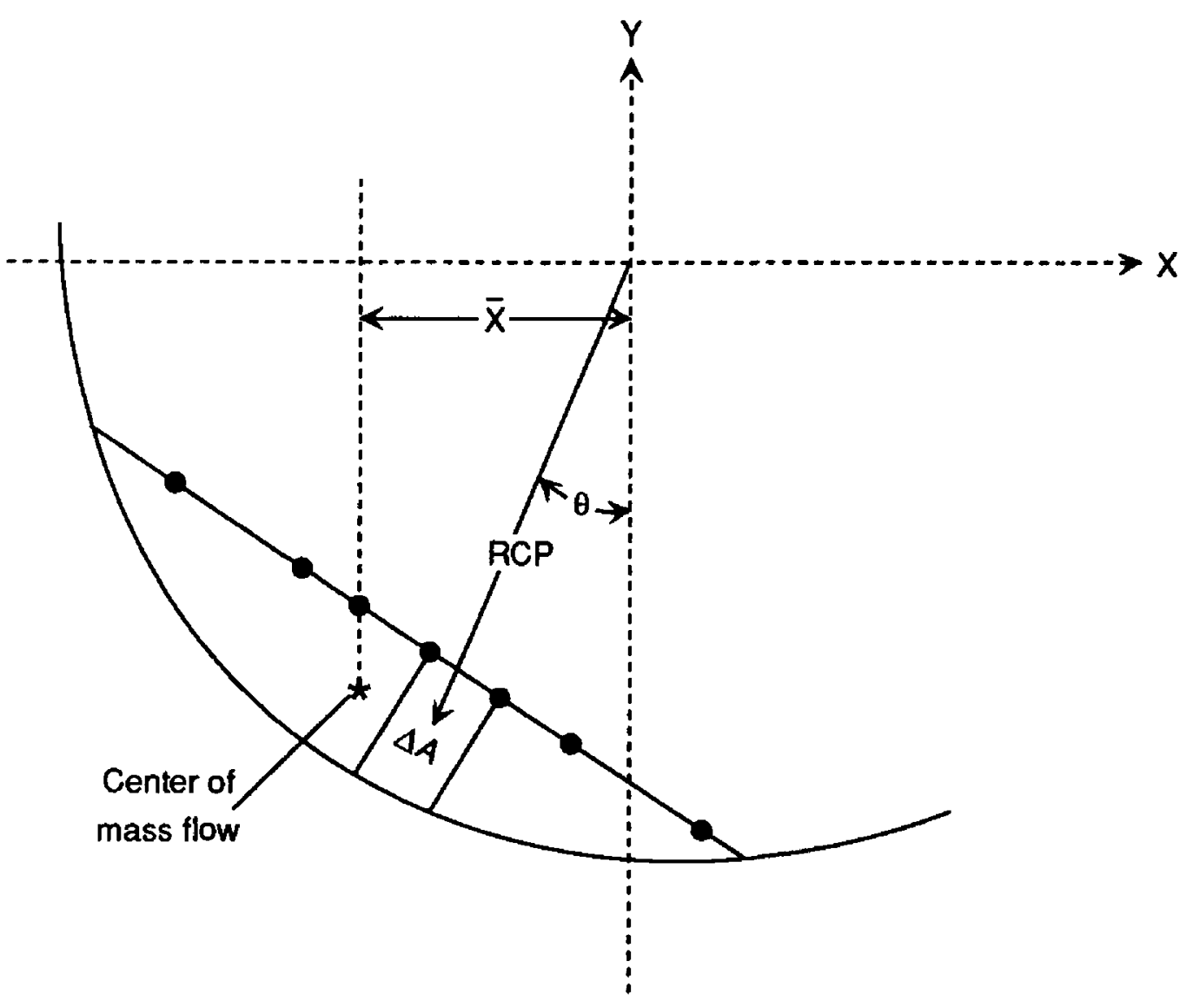

EXPLANATION

- DIGITIZED POINT

$\triangle A$ EXAMPLE PARTIAL AREA

RCP RADIUS TO THE CENTER OF THE PARTIAL AREA

$\bar{X}$ MOMENT ARM FROM THE $Y$ AXIS TO THE CENTER OF MASS FLOW

$\theta$ ANGLE TO CENTER OF MASS FLOW FOR THE EXAMPLE PARTIAL AREA

Figure 6.--Flow material profile and example partial area. 
$A_{S}$ SURFACE AREA OF ONE SIDEWALL IN SQUARE METERS OF THE MASS FLOW-PROFILE EQUAL TO THE SUM OF $\triangle A$ (fig. 6)

$A_{b}$ BOTTOM SURFACE AREA IN SQUARE METERS OF THE MASS FLOW

$\tau_{s}$ SHEAR STRESS IN DYNES PER SQUARE METERS ALONG THE SIDES OF THE MASS FLOW

$\tau_{b}$ SHEAR STRESS IN DYNES PER SQUARE METERS ALONG THE BOTTOM OF THE FLUME $\phi_{t}$ ANGLE TO THE TAIL

$\theta$ ANGLE TO THE CENTER OF THE MASS FLOW FROM THE Y AXIS

R RADIUS IN METERS TO THE FLUME BOTTOM

Rc RADIUS IN METERS TO THE CENTER OF THE MASS FLOW

WT WIDTH IN METERS OF THE FLUME

W WEIGHT OF MASS FLOW IN GRAMS

$\phi_{S}$ ANGLE TO THE SNOUT

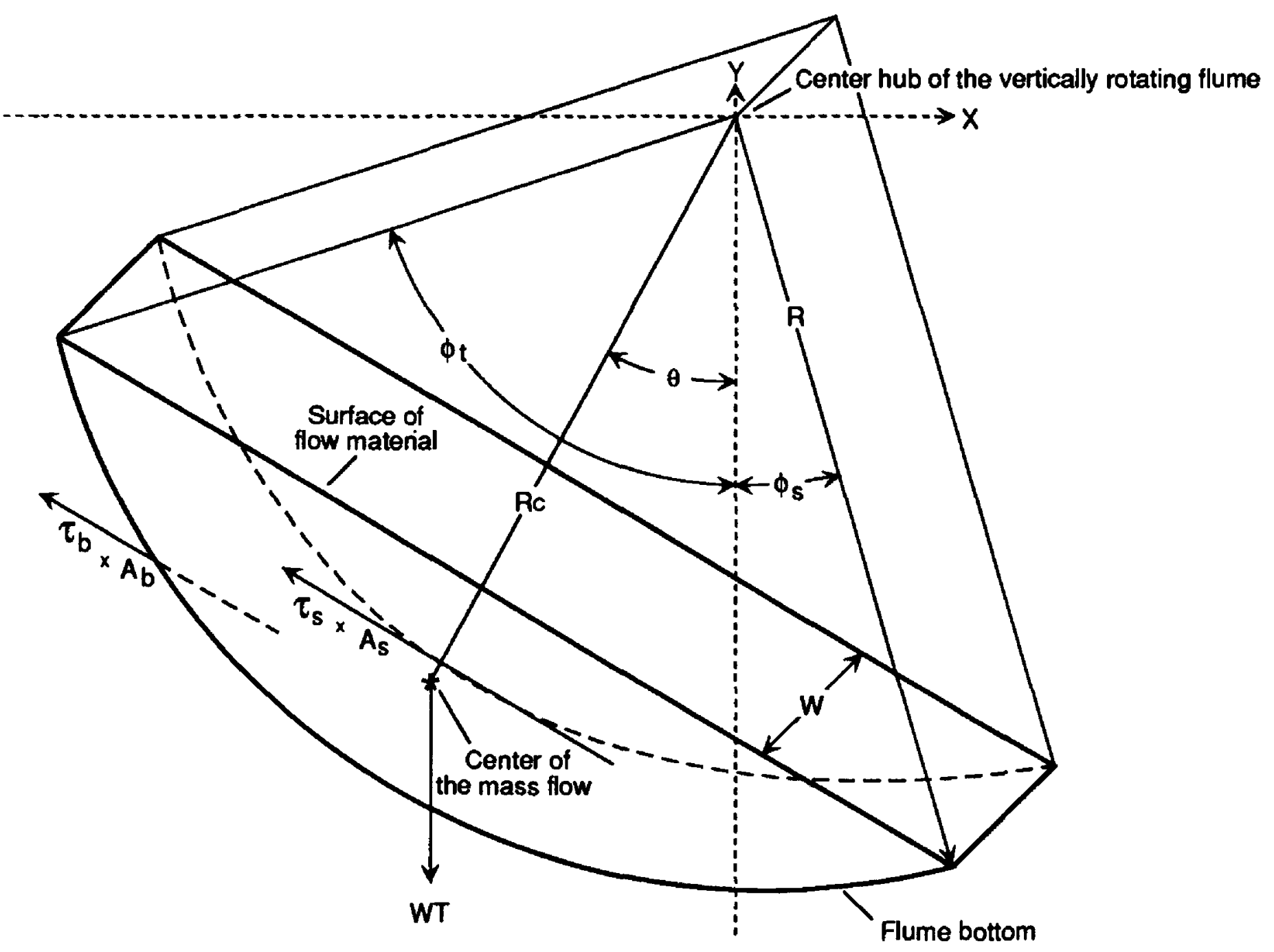

Figure 7.--Free-body diagram of the forces on the flow material. 
Summing the moments yields

$$
\begin{aligned}
& \mathrm{WT} \times \mathrm{R}_{\mathrm{c}} \times \sin \theta=\tau_{\mathrm{b}} \times \mathrm{R} \times \mathrm{R} \times \mathrm{W} \times\left(\phi_{\mathrm{s}}+\phi_{\mathfrak{t}}\right)+ \\
&\left(2 \times \tau_{\mathrm{s}} \times \mathrm{R}_{\mathrm{c}} \times \mathrm{A}_{\mathrm{s}}\right) .
\end{aligned}
$$

Assuming that

$$
\tau_{b}=\tau_{s}=\tau,
$$

where $\tau$ is the average shear stress, in dynes per square meter resisting flow, equation 2 reduces to

$$
\begin{aligned}
& \mathrm{WT} \times \mathrm{R}_{\mathrm{c}} \times \sin \theta=\tau \times\left[\mathrm{W} \times \mathrm{R}^{2} \times\left(\phi_{\mathrm{s}}+\phi_{\mathrm{l}}\right)+\right. \\
&\left.\left(2 \times \mathrm{A}_{\mathrm{s}} \times \mathrm{R}_{\mathrm{c}}\right)\right] .
\end{aligned}
$$

Because

$$
\mathrm{WT} \times \mathrm{R}_{\mathrm{c}} \times \sin \theta=\Sigma \mathrm{M}_{\mathrm{y}} \times \mathrm{W} \times \gamma,
$$

where $\gamma$ is the unit weight, in dynes per cubic meter, $\Sigma \mathrm{M}_{\mathrm{y}} \times \mathrm{W} \times \boldsymbol{\gamma}$ can be substituted into equation 4 to yield

$$
\begin{gathered}
\Sigma M_{y} \times W \times \gamma=\tau \times\left[W \times R^{2} \times\left(\phi_{s}+\phi_{t}\right)+\right. \\
\left.\left(2 \times A_{s} \times R_{c}\right)\right] .
\end{gathered}
$$

Rearranging equation 6 and solving for $\tau$, the equation for shear stress is

$$
\tau=\frac{\left(\Sigma \mathrm{M}_{\mathrm{y}} \times \mathrm{W} \times \gamma\right)}{\left[\mathrm{W} \times \mathrm{R}^{2} \times\left(\phi_{\mathrm{s}}+\phi_{\mathrm{l}}\right)+\left(2 \times \mathrm{A}_{\mathrm{s}} \times \mathrm{R}_{\mathrm{c}}\right)\right]} \text {.(7) }
$$

\section{Straln Rate Calculation}

Assuming a hydrostatic pressure distribution, the shear stress in the fluid varies linearly with depth with a maximum at the flume bottom. Assuming the relation between shear stress and strain rate is constant (for example, Bingham plastic or Newtonian fluid), a parabolic velocity profile can be used (Johnson, 1970). Furthermore, it is seen that the strain rate is a maximum where the shear stress is a maximum (fig. 1). Because the shear stress is a maximum at the flume bottom, the strain rate also is a maximum at the flume bottom.

Based on these assumptions, materials with plug flow (exhibiting yield strength; for example, Bingham plastic) have a velocity distribution as shown in figure 8. Materials without plug flow (no yield strength; for example, Newtonian fluid) have a similar velocity distribution without the plug flow component. Both these profiles assume no slippage of material at the flume bottom/flow material interface. However, no feasible experiment has been formulated to test this assumption to date (1992).

Using the parabolic velocity distribution and assuming laminar flow, the strain rate at the flume bottom can be calculated. Local strain rates are calculated at $10-\mathrm{mm}$ increments along the deepest 20 percent (20 percent of distance from snout to tail) of the interface between the flume bottom and flow material.

\section{Materiais with piug flow}

For materials with plug flow, the velocity distribution relative to the VRF bottom is shown in figure 8 . The velocity vectors used in the strain rate calculation scheme, the parabolic velocity distribution with plug flow, and the point of reference are shown in figure 9.

Using the parabolic velocity distribution with plug flow, an equation to estimate the velocity at any depth, $Y$, can be derived. The velocity, relative to the VRF bottom (fig. 10), at any depth below the plug flow layer is

$$
\mathrm{V}=\mathrm{U}_{\mathrm{t}}-\Delta,
$$

where

$\mathrm{V}$ is velocity, in meters per second, relative to the VRF bottom;

$U_{t}$ is velocity at surface of material, relative to the VRF bottom, in meters per second (this is equal to the VRF velocity, $U_{f}$, plus the measured surface velocity relative to the laboratory floor, $\mathrm{U}_{\mathrm{s}}$ ); and

$\Delta$ is a coordinate, in the direction opposite to that velocity, used to describe the velocity curve below the plug flow layer.

By placing the origin of the $(\Delta, Y)$ coordinate system at the interface between the plug flow section and the deforming flow section (fig. 10), a parabolic velocity distribution gives an equation of

$$
\Delta=\mathbf{a} \mathbf{Y}^{2},
$$




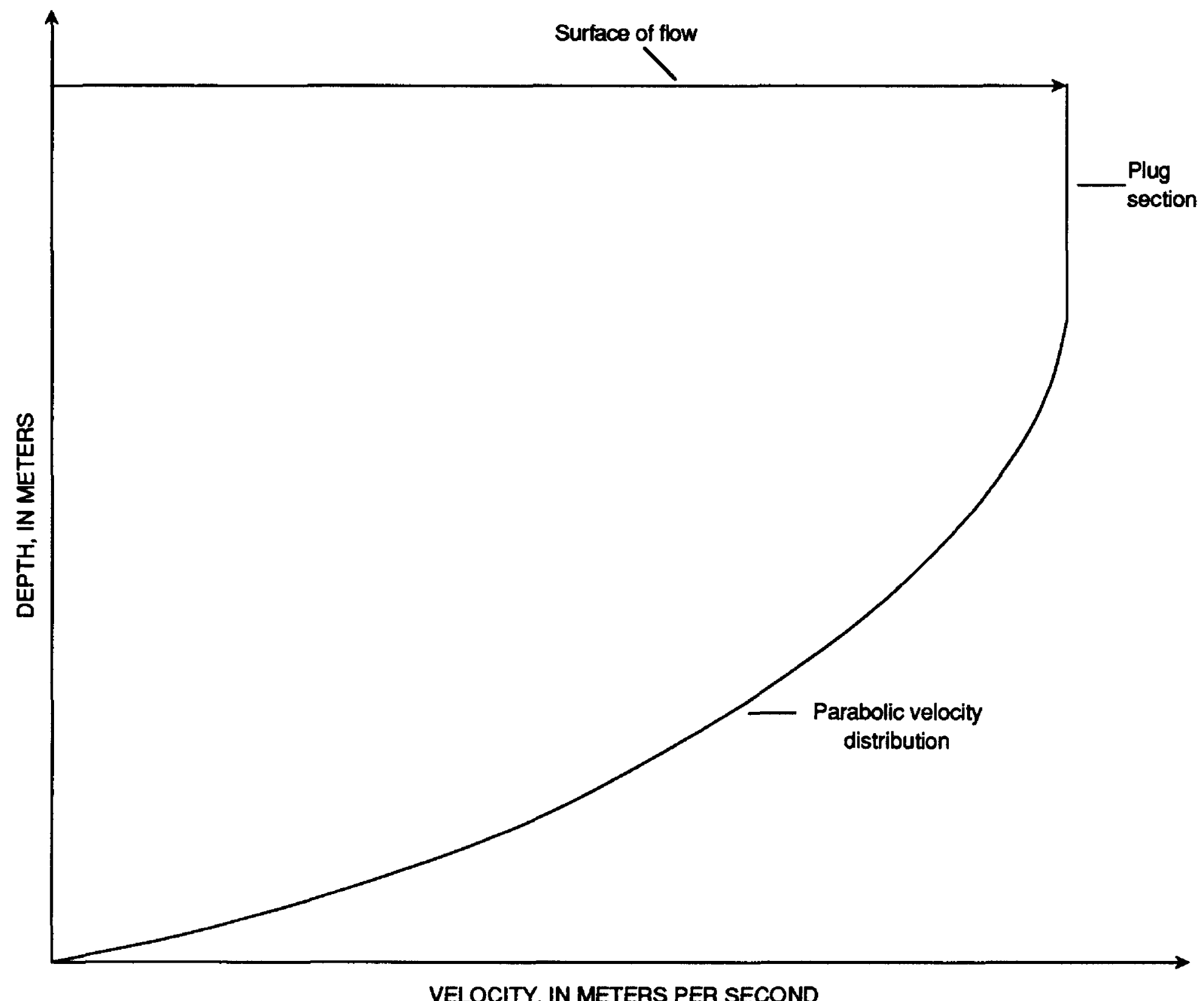

VELOCITY, IN METERS PER SECOND

Figure 8.--Parabolic velocity distribution of a material with plug flow (exhibiting yield strength). 


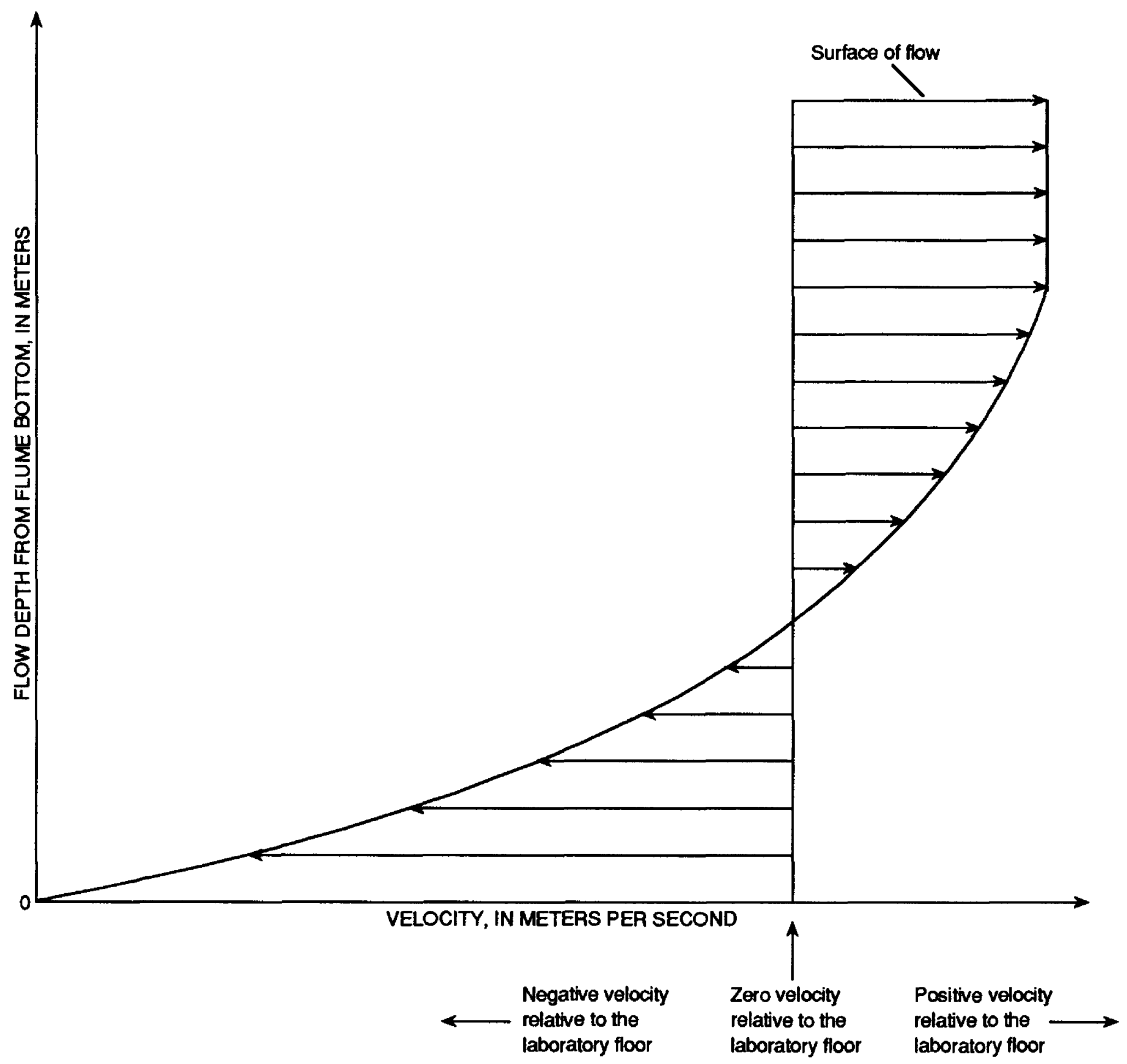

Figure 9.--Parabolic velocity distribution of a material exhibiting plug flow, relative to the laboratory floor. 


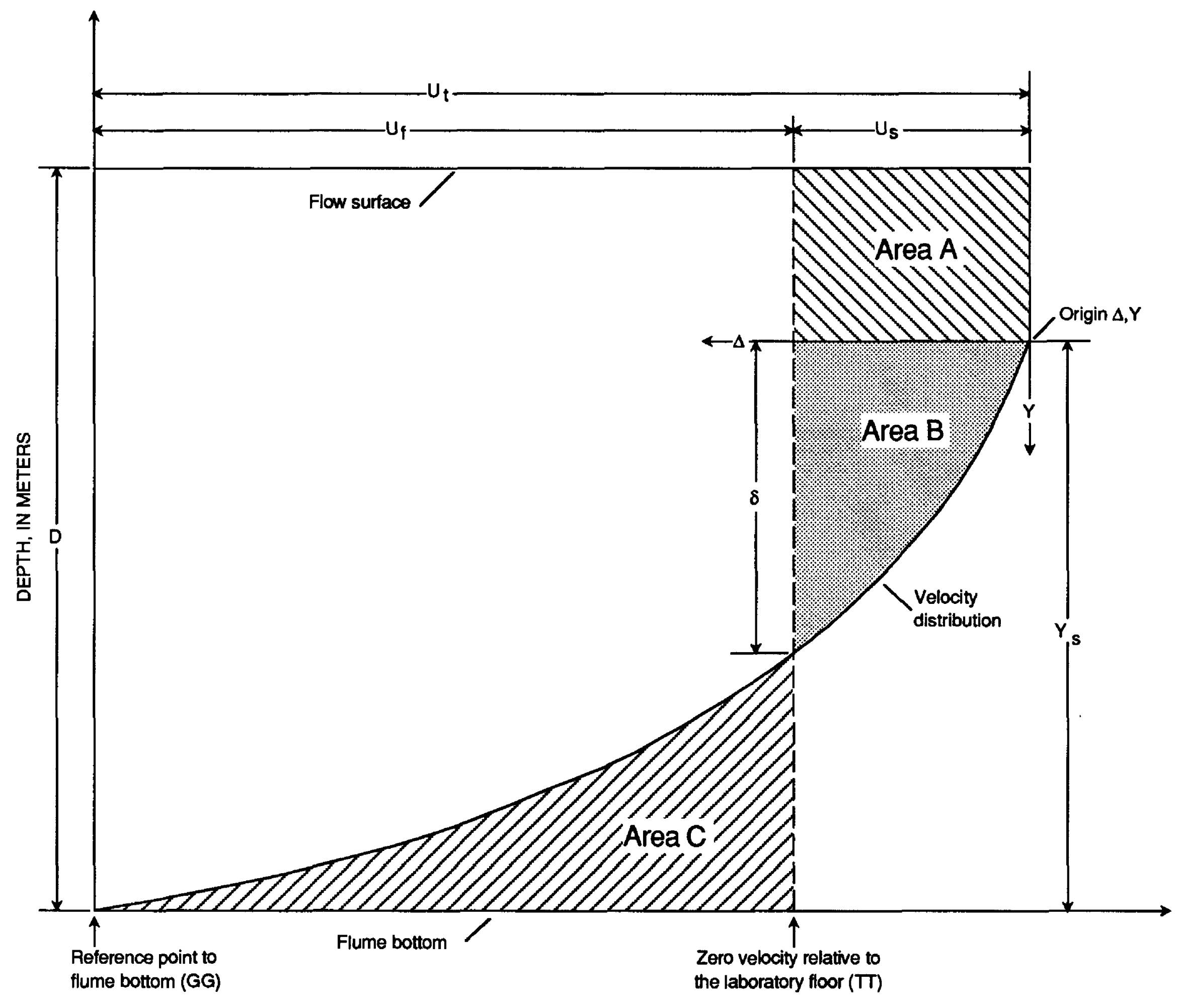

VELOCITY, IN METERS PER SECOND

EXPLANATION

D DEPTH OF FLOW

$U_{f}$ VERTICALLY ROTATING FLUME VELOCITY RELATIVE

TO THE LABORATORY FLOOR

US MATERIAL SURFACE VELOCITY RELATIVE TO

THE LABORATORY FLOOR

Ut VELOCITY AT THE SURFACE OF THE MATERIAL RELATIVE

TO THE VERTICALLY ROTATING FLUME BOTTOM

$\triangle$ COORDINATE IN OPPOSITE DIRECTION FROM VELOCITY

$Y$ COOORDINATE IN DIRECTION OF DECREASING DEPTH

$Y_{S}$ DEPTH OF NON-PLUG FLOW LAYER

$\delta$ DISTANCE FROM MEAN VELOCITY TO BOTTOM OF PLUG

FLOW LAYER

Figure 10.--Relation of velocity vectors to the vertically rotating flume bottom and the laboratory floor as a reference point. 
where

a is constant; and

$\mathrm{Y}$ is a coordinate value where positive is in the direction of decreasing depth.

At $Y$ equal to $Y_{s}, \Delta$ equals $U_{t}$; therefore, substitution of these two values for "a" into equation 9 yields

$$
\Delta=\frac{\mathrm{U}_{\mathrm{t}}}{\mathrm{Y}_{\mathrm{s}}^{2}} \mathrm{Y}^{2},
$$

where $Y_{s}$ is depth of the flow, in meters, from the bottom of the plug flow layer to the bottom of the VRF.

Equation 8 becomes

$$
\mathrm{V}=\mathrm{U}_{\mathrm{t}}-\frac{\mathrm{U}_{\mathrm{t}}}{\mathrm{Y}_{\mathrm{s}}^{2}} \mathrm{Y}^{2}
$$

The strain rate at any depth, Y, can be determined by taking the derivative with respect to $Y$ of equation 11 ,

$$
\frac{d V}{d Y}=-\frac{2 U_{t}}{Y_{s}^{2}} Y .
$$

Because interest is the strain rate at the boundary layer, evaluation of equation 12 at $Y=Y_{s}$ is made, resulting in

$$
\frac{d V}{d Y}=-\frac{2 U_{t}}{Y_{s}} .
$$

The value of $U_{t}$ can be calculated from measurements in the VRF, but $Y_{s}$, the depth of flow below the plug flow layer, is not easily measurable. Therefore, a relation of $Y_{s}$ to measurable values in the VRF must be determined.

In the VRF, a unique steady-state condition is established where the absolute flow rate past any point is zero, which implies the mean velocity past any point also is zero. As the material passes point TT in the VRF (fig. 10), areas A and B represent the part of the velocity curve, relative to the laboratory floor, flowing in the positive direction. Area $\mathrm{C}$ represents the part of the velocity curve, relative to the laboratory floor, flowing in the negative direction.
Because the mean velocity relative to the laboratory floor is zero, area A plus area B must equal area C. Mathematically equating the three areas based on measurable aspects of the flow enables the formulation of an equation for $Y_{s}$.

To equate the three areas, a relation for $\delta$, distance from the bottom of the plug flow layer to the location of zero velocity relative to the laboratory floor (fig. 10), must be determined. If $Y$ equals $\delta$ then $\Delta$ equals $\mathrm{U}_{\mathrm{s}}$, and the following relation is realized from equation 10 :

$$
\delta=\sqrt{\frac{\mathrm{U}_{\mathrm{s}}}{\mathrm{U}_{\mathrm{t}}}} \mathrm{Y}_{\mathrm{s}},
$$

and the three areas shown in figure 10 can be equated using this and other relations derived earlier.

Area $A$ can be expressed from figure 10 as follows:

$$
A=U_{s}\left(D-Y_{s}\right)
$$

where
A is the longitudinal area of the non- deforming plug, flowing in the positive direction; and
D is depth of flow below the surface, in meters.

Area B can be expressed from figure 10 as follows:

$$
\mathrm{B}=\mathrm{U}_{\mathrm{s}} \delta-\int_{0}^{\delta} \frac{\mathrm{U}_{\mathrm{t}}}{\mathrm{Y}_{\mathrm{s}}^{2}} \mathrm{Y}^{2} \mathrm{~d} \mathrm{Y} .
$$

This reduces to

$$
B=U_{s} \delta-\frac{U_{t} \delta^{3}}{3 Y_{s}^{2}}
$$

Because

$$
\delta=\sqrt{\frac{U_{s}}{U_{t}}} Y_{s},
$$


substituting equation 14 into equation 17 and simplifying yields

$$
B=\frac{2 U_{s}^{3 / 2}}{3 U_{t}^{1 / 2}} Y_{s} .
$$

Area $\mathrm{C}$ can be expressed from figure 10 as

$$
C=\int_{\delta}^{Y_{s}} \frac{U_{t}}{Y_{s}^{2}} Y^{2} d Y-U_{s} Y_{s}\left(1-\sqrt{\frac{U_{s}}{U_{t}}}\right) .
$$

This reduces to

$$
\begin{gathered}
C=\frac{U_{t} Y_{s}}{3}-\frac{U_{t}}{3 Y_{s}^{2}}\left(\frac{U_{s}}{U_{t}}\right)^{3 / 2} Y_{s}^{3}-U_{s} Y_{s}+ \\
U_{s} Y_{s} \sqrt{\frac{U_{s}}{U_{t}}},
\end{gathered}
$$

and simplifying and rearranging equation 20 yields

$$
\mathrm{C}=\frac{\mathrm{U}_{\mathrm{t}} \mathrm{Y}_{\mathrm{s}}}{3}+\frac{2 \mathrm{U}_{\mathrm{s}}^{3 / 2}}{3 \mathrm{U}_{\mathrm{t}}^{1 / 2}} \mathrm{Y}_{\mathrm{s}}-\mathrm{U}_{\mathrm{s}} \mathrm{Y}_{\mathrm{s}}
$$

From the steady-state system shown in figure 10, by conservation of mass, substitution of equations 15 , 18 , and 21 into equation 22 produces

$$
\begin{gathered}
\mathrm{A}+\mathrm{B}=\mathrm{C}, \\
\mathrm{U}_{\mathrm{s}}\left(\mathrm{D}-\mathrm{Y}_{\mathrm{s}}\right)+\frac{2 \mathrm{U}_{\mathrm{s}}^{3 / 2}}{3 \mathrm{U}_{\mathrm{t}}^{1 / 2}} \mathrm{Y}_{\mathrm{s}}= \\
\frac{\mathrm{U}_{\mathrm{t}} \mathrm{Y}_{\mathrm{s}}}{3}-\frac{2 \mathrm{U}_{\mathrm{s}}^{3 / 2}}{3 \mathrm{U}_{\mathrm{t}}^{1 / 2}} \mathrm{Y}_{\mathrm{s}}-\mathrm{U}_{\mathrm{s}} \mathrm{Y}_{\mathrm{s}} .
\end{gathered}
$$

Equation 23 can be reduced and solved for $Y_{s}$,

$$
Y_{s}=\frac{3 U_{s} D}{U_{t}}
$$

The substitution of equation 23 into equation 13 produces the equation for strain rate at the boundary layer for materials with a parabolic velocity distribution and plug flow (the negative sign is ignored because of orientation of the axis)

$$
\frac{d V}{d Y}=\frac{2 U_{t}^{2}}{3 U_{s} D} \text {. }
$$

\section{Materials without Plug Flow}

For materials with a parabolic velocity distribution and no plug flow, such as a laminar Newtonian fluid, the velocity profile relative to the VRF bottom is shown in figure 11 . Because the velocity dis- tribution is parabolic, equation 13 can be used for materials without plug flow

$$
\frac{d V}{d Y}=-\frac{2 U_{t}}{Y_{s}}
$$

Because there is no plug flow layer, $Y_{S}=D$. The negative sign is ignored because of orientation of the axis and equation 13 is rewritten to

$$
\frac{d V}{d Y}=\frac{2 U_{t}}{D}
$$

which is the equation for strain rate at the boundary layer for materials with parabolic velocity distribution and no plug flow.

\section{Potential Computational Deficlencles Re- sulting from Simpllfying Assumptlons}

Certain simplifying assumptions were made during this research so that the laboratory data could be reduced to shear stress and strain rate values. These assumptions, which include those of steady-state condition and one-dimensional flow, are discussed here along with the potential deficiencies involved.

The assumption of a steady-state condition is made to simplify the computation of the shear stress and strain rate. Although the flume speed remained constant, some surging (generally less than $0.04 \mathrm{~m}$ ) of the flow in the longitudinal direction occurs at the higher flume wheel velocities. This surging of flow affects the computation of shear stress and strain rate because the geometry and location of the mass varies. However, during experiments it was determined that an acceptable average shear stress and strain rate can be determined when at least five photographs are taken, calculations are made for each photograph, and the average strain rate and shear stress are computed.

One-dimensional flow also is assumed for purposes of simplifying computation of shear stress and strain rate. Surface irrotational flow was noted in the vicinity of the side walls and extended toward the center of the flow as much as $0.04 \mathrm{~m}$, depending on longitudinal location and flume wheel velocity. Currently (1992), two- and three-dimensional methods are being postulated and evaluated in an attempt to deal with this multidimensional flow. 


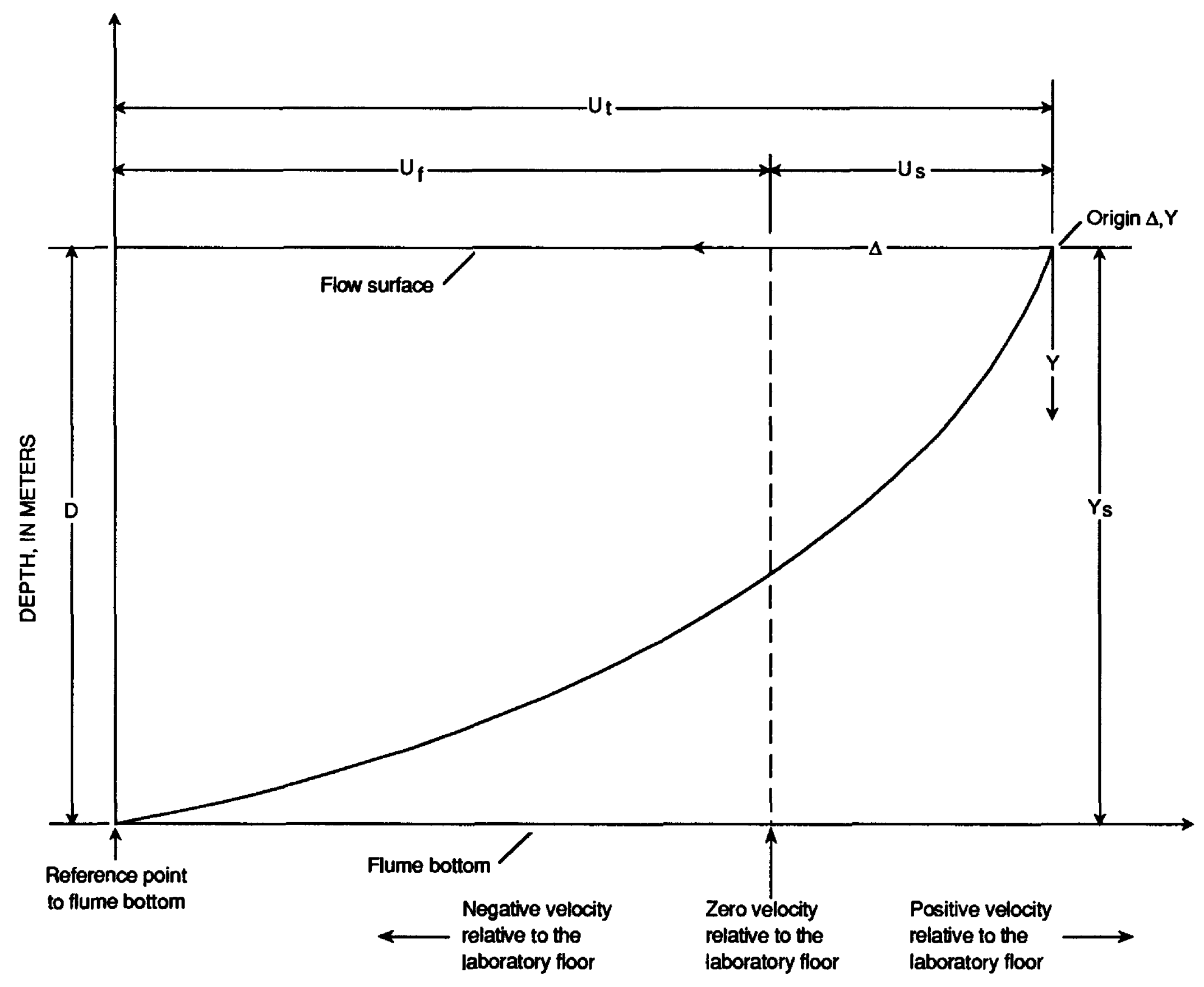

VELOCITY, IN METERS PER SECOND

EXPLANATION

D DEPTHOF FLOW

$U_{f}$ VERTICALLY ROTATING FLUME VELOCITY RELATIVE

TO THE LABORATORY FLOOR

US MATERIAL SURFACE VELOCITY RELATIVE TO

THE LABORATORY FLOOR

$U_{t}$ VELOCITY AT THE SURFACE OF THE MATERIAL RELATIVE

TO THE VERTCALLY ROTATING FLUME BOTTOM

$\triangle$ COORDINATE IN OPPOSITE DIRECTION FROM VELOCITY

$Y$ COORDINATE IN DIRECTION OF DECREASING DEPTH

YS DEPTH OF NON-PLUG FLOW LAYER

Figure 11.--Parabolic velocity distribution of a material with no plug flow and the relation of the velocity vectors to the vertically rotating flume bottom and the laboratory floor. 
However, accompanying the added dimensions are new unknown parameters added to the equations, and the solution techniques become inherently more complicated.

\section{SUMMARY}

Determining the rheologic properties of coarse-grained mass flows is an important step to mathematical simulation of potential inundation zones. The VRF, a vertically rotating flume, designed and built by the U.S. Geological Survey, can aid in understanding the rheology of coarse-grained materials. The laboratory procedures and data-collection techniques have been developed during several experiments. The photogrammetric technique to determine the actual geometry of a flow surface profile is accurate to within $0.003 \mathrm{~m}$. Techniques to reduce the raw laboratory data into shear stress and strain rate are based on physics of the flow material in the VRF accompanied by simplifying assumptions, which include a steady-state system and one-dimensional flow in the VRF. Strain rate and shear stress computations are developed for flows with and without a plug layer. Potential computational deficiencies resulting from these simplifying assumptions include effects of surging and multidimensional flow.

\section{REFERENCES}

Johnson, A.M., 1970, Physical processes in geology: San Francisco, Freeman, Cooper and Co., 576 p.

Rudolfo, K.S., 1989, Origin and early evolution of lahar channel at Mabinit, Mayon Volcano, Philippines: Geological Society of America Bulletin, v. 101, p. 414-426.

Shlemon, R.J., Wright, R.H., and Montgomery, D.R., 1987, Anatomy of a debris flow, Pacifica, Calif.: Geological Society of America Reviews in Engineering Geology, v. 7, p. 181-199. 